\title{
EDITORIAL
}

\section{An editorial anomaly}

Most of the science in the Latin-American region is funded with public money, and the institutions that provide the money have little or no record of the resulting published material. In a time when the open access initiative is gaining momentum and is advocated by financing institutions, the Argentine Association for the Progress of Science (AAPC) evaluated that launching a new publication was warranted, with distinctive features that make it an editorial anomaly:

1. Regional scientific journals mainly focus on the publication of research that, though relevant for the region, is not original enough to meet the standards of top journals. Our journal seeks to present highly relevant material, originated in the region but with global impact: authoritative, timely reviews of the fields of research by prestigious scientist that may constitute an important archive of the science carried out in the region.

2. All fields of science are included. We believe that well written reviews are of widespread interest, not restricted to specialists in a narrow discipline; however, topical issues are expected to appear alongside with other, more general issues.

3. Rather than focusing on the publication of marginal science - an unfortunate very widespread trend - our target authors are the most influential ones, those that currently publish in top journals from the learned societies or from the few large editorial houses. Thus, papers are received mainly by invitation and subjected to rigorous review.

4. The members of the Editorial Board are very prestigious scientists, currently from Argentina, with the possibility of enlarging it to include scientist from other countries in the region as well.

5. Open access is guaranteed; furthermore, the fast dissemination of the oncoming publications is achieved by personalized mailing lists.

The journal we now launch has become a reality in the form of a joint venture between AAPC and Centro Redes Foundation, a prestigious institution that is heavily involved in scientometric analyses for the region. Financing was provided by the Science, Technology and Productive Innovation Government Secretary.

The first issue collects four reviews on timely aspects of various fields of science and technology. I hope you enjoy them.

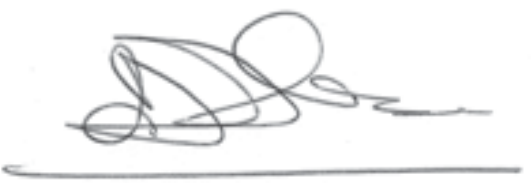

Miguel A. Blesa

Editor-in-Chief 